\title{
A dose ranging study of ibuprofen suspension as an antipyretic
}

\author{
S C Marriott, T J Stephenson, D Hull, R Pownall, C M Smith, A Butler
}

\begin{abstract}
A double blind trial was conducted to determine the dose of ibuprofen suspension, which is effective in reducing the body temperature. The principal measure of efficacy was a reduction in axillary temperature of $1^{\circ} \mathrm{C}$ or more three hours after dosing. A second objective of the trial was to compare the incidence and severity of side effects and the palatability of a range of ibuprofen doses.

Ninety three children were included in the analysis. All four doses of ibuprofen studied $(0.625 \mathrm{mg} / \mathrm{kg}-5 \mathrm{mg} / \mathrm{kg})$ were associated with temperature reduction and only the lowest dose failed to satisfy the principal measure of efficacy. The influence of dose on the magnitude of the body temperature reduction was significant and the $5 \mathrm{mg} / \mathrm{kg}$ dose achieved the largest mean reduction in body temperature $\left(2^{\circ} \mathrm{C}\right)$. The tolerability and palatability of all doses studied were excellent. These findings suggest that ibuprofen is a good alternative to paracetamol as an antipyretic.
\end{abstract}

Fever is one of the commonest features of illness in children, leads to many hospital admissions, and engenders a great deal of parental anxiety. It remains controversial whether fever causes or is simply associated with febrile convulsions, ${ }^{1}$ but much time and effort are spent in reducing the temperature of these children and there is reluctance to discharge such children until they are apyrexial.

With the recognition that aspirin in febrile children is associated with an increased incidence of Reye's syndrome, ${ }^{2}$ paracetamol became the only antipyretic agent used routinely in children. If a more potent antipyretic, which was as safe or safer than paracetamol, was available then this would be a valuable addition to the paediatric formulary. If such a drug also had powerful anti-inflammatory and analgesic actions, other symptoms often associated with fever would also be alleviated.

Ibuprofen is a propionic acid derivative that has been used to relieve inflammation and pain for over 20 years and has been available for the treatment of juvenile rheumatoid arthritis since 1979. Although it has also been known for some time that ibuprofen has powerful antipyretic effects in both animal models ${ }^{34}$ and children, ${ }^{5}$ this non-steroidal anti-inflammatory drug has not had a UK product licence for this purpose in children until 1990.

There have been a number of trials that have compared the antipyretic properties of ibupro- fen with paracetamol in children ${ }^{5-8}$ and this was not the purpose of this present study. It has been established by these trials that ibuprofen compares favourably with paracetamol but the minimum ibuprofen dose that is effective and the comparative tolerance over a range of doses have not been established. We present the results of a double blind trial, the main aim of which was to determine the minimum dose of oral ibuprofen suspension that is effective in reducing fever in children. A second objective was to compare the incidence and severity of side effects of a range of doses.

\section{Patients and methods}

The trial was conducted at the University Hospital, Nottingham, and had the approval of the Nottingham Hospitals ethics committee. Written, informed consent was obtained from a parent or guardian.

In recognition of the difficulties in defining the normal body temperature range of children at different times of day and in different thermal environments, the principal index of antipyretic efficacy chosen was a reduction in body temperature of $1^{\circ} \mathrm{C}$ or more within three hours of the dose rather than an absolute body temperature. This criterion was defined before the study.

Children of either sex were eligible provided that the axillary temperature on admission to the ward was $37.5^{\circ} \mathrm{C}$ or more. A body weight less than $8 \mathrm{~kg}$ precluded entry to the trial and no child was studied twice. Children were also ineligible if there were relative contraindications to oral non-steroidal anti-inflammatory drugs (bleeding disorder; hepatic, renal or cardiac disease; peptic ulceration; recurrent severe bronchospasm; receiving immunosuppressant treatment, bronchodilators, digoxin or diuretics; previous adverse reaction to aspirin or nonsteroidal anti-inflammatory drugs). Children were not excluded if they had received previous antipyretics, antibiotics, or other concomitant drug treatment. Entry to the trial was immediately after the eligibility assessment except when paracetamol or aspirin had been given in the previous four hours in which case these drugs were discontinued and a washout period of four hours was allowed. There were no children taking non-steroidal anti-inflammatory drugs at the time of entry to the trial.

Randomisation to treatment was arranged so that equal numbers of patients were allocated to receive one of four strengths of ibuprofen suspension: $2.5 \mathrm{mg} / \mathrm{ml}, 5 \mathrm{mg} / \mathrm{ml}, 10 \mathrm{mg} / \mathrm{ml}$, or 20 $\mathrm{mg} / \mathrm{ml}$. An appropriate volume of suspension of one of these strengths was given, depending on 
body weight, such that the children were effectively randomly allocated to receive one of four doses of ibuprofen suspension: $0.625 \mathrm{mg} / \mathrm{kg}$, $1.25 \mathrm{mg} / \mathrm{kg}, 2.5 \mathrm{mg} / \mathrm{kg}$, or $5.0 \mathrm{mg} / \mathrm{kg}$. The four study medications were identical opaque orange syrups and similar in taste. Medications were administered using a plastic measuring cylinder and $5 \mathrm{ml}$ of water used to rinse any residual volume of medication from the dispenser. The randomised dose to which the child was allocated was repeated six hours after the initial dose.

It was considered unethical to include a placebo control group. To meet the concern that the weaker ibuprofen regimens might prove ineffective a supplementary medication was provided by ibuprofen $2.5 \mathrm{mg} / \mathrm{kg}(10 \mathrm{mg} / \mathrm{ml}$ strength of suspension). In the event that the axillary temperature remained above $37 \cdot 2^{\circ} \mathrm{C}$ three hours after the initial randomised dose of ibuprofen, a 'rescue' dose of supplementary medication could be administered. If the child was given this 'rescue' dose, no medication was given at six hours after the initial randomised dose but the child received a second dose of the supplementary medication at nine hours.

The demographic data collected on entry to the trial consisted of age, sex, body weight, and concomitant treatment. The axillary temperatures of the children were recorded using a digital thermometer (Comark Products International) immediately before the initial dose (baseline) and at $0.25,0.5,1,2,3,4,6,9$, and 12 hours after the initial randomised dose of ibuprofen. These measurements were very reproducible (within observer variation $\pm 0 \cdot 1^{\circ} \mathrm{C}$ ). The clinical condition of the child was evaluated 3,6 , and 12 hours after the initial dose by one 'blind' investigator (SCM) on a five point scale with categories much worse, worse, no change, improved, and much improved. The acceptability of the medication to the child was assessed by the same investigator on a five point scale (very acceptable, acceptable, indifferent, unacceptable, very unacceptable) at the initial and repeat dosings.

All adverse clinical events that occurred during the 12 hour period of the trial were recorded irrespective of whether or not these events were considered to be a side effect of ibuprofen. The case notes of children for whom an adverse event was recorded were subsequently reviewed by one of us (DH), who remained 'blind' to which dose of ibuprofen the children had been randomised and who made an assessment of whether the adverse event was part of the natural history of the child's condition or a side effect of ibuprofen.
STATISTICAL ANALYSIS

The effect of different doses on the number of patients withdrawing were compared using the $\chi^{2}$ test. The change in temperature at three hours from baseline was analysed for each dose of ibuprofen using the paired $t$ test and 95\% confidence intervals were calculated for the mean differences between baseline axillary temperature and the temperature at three hours. Differences between doses in the temperature at three hours, the clinical condition at three hours, and the acceptability of the medication were tested by analysis of covariance, using age and baseline temperature as the covariates. Differences between doses in the number of children who warranted supplementary medication were compared using the $\chi^{2}$ test. The effects of different doses on the number of children suffering adverse clinical events were compared using the $\chi^{2}$ test.

\section{Results}

One hundred children were recruited into the study. Seven of the children who had been entered did not, in retrospect, fulfil the eligibility criteria. The 93 remaining children ( 57 boys and 36 girls) were included in the analysis. Their mean (SD) age was $2.6(1 \cdot 7)$ years, mean body weight $13 \cdot 1(4 \cdot 2) \mathrm{kg}$, and mean baseline axillary temperature $38.6(0.7)^{\circ} \mathrm{C}$. Twenty two (24\%) of these children were already receiving some medication when recruited to the study. The four treatment groups showed no significant differences in age, weight, baseline, axillary temperature, or frequency of concomitant treatment (table 1).

\section{WITHDRAWALS FROM THE TRIAL}

Of the 93 eligible children who received a first randomised dose of ibuprofen, 18 children were withdrawn from the trial by the clinical investigator before the 12 hour study period was completed. The reasons were lack of response, as judged by an axillary temperature persisting above $37 \cdot 2^{\circ} \mathrm{C}$ despite a 'supplementary' dose of ibuprofen at three hours $(n=13)$ or an adverse event $(n=5)$. In addition, one child made a complete recovery and was discharged from hospital before completion of the 12 hour period, and there were incomplete data for a further four children. In total, therefore, the data set analysed was incomplete for 23 of the 93 children deemed eligible to enter the study. There was no significant preponderance of these 23 children among the four treatment groups (table 2).

Table 1 Demographic data of children eligibly entered into the trial

\begin{tabular}{lccccc}
\hline & \multicolumn{2}{c}{ Ibuprofen dose $(\mathrm{mg} / \mathrm{kg})$} & & & \\
& $0 \cdot 625$ & $1 \cdot 25$ & $2 \cdot 5$ & $5 \cdot 0$ & All \\
\hline Mean (SD) age (years) & $2 \cdot 4(1 \cdot 3)$ & $2 \cdot 7(1 \cdot 8)$ & $2 \cdot 5(1 \cdot 8)$ & $2 \cdot 8(2 \cdot 1)$ & $2 \cdot 6(1 \cdot 7)$ \\
Mean (SD) weight (kg) & $13 \cdot 1(3 \cdot 6)$ & $12 \cdot 6(3 \cdot 1)$ & $12 \cdot 7(3 \cdot 6)$ & $14 \cdot 0(5 \cdot 9)$ & $13 \cdot 1(4 \cdot 2)$ \\
Mean (SD) baseline temperature $\left({ }^{\circ} \mathrm{C}\right)$ & $38 \cdot 5(0 \cdot 6)$ & $38 \cdot 6(0 \cdot 6)$ & $38 \cdot 4(0 \cdot 7)$ & $39 \cdot 0(0 \cdot 9)$ & $38 \cdot 6(0 \cdot 7)$ \\
No of children entered & 26 & 20 & 24 & 23 & 93 \\
No receiving concomitant treatment & 5 & 7 & 7 & 3 & 22 \\
\hline
\end{tabular}


Table 2 Reasons for withdrawal of patients from study

\begin{tabular}{|c|c|c|c|c|c|}
\hline & \multicolumn{4}{|c|}{ Ibuprofen dose $(\mathrm{mg} / \mathrm{kg})$} & \multirow[b]{2}{*}{ All } \\
\hline & 0.625 & $1 \cdot 25$ & $2 \cdot 5$ & $5 \cdot 0$ & \\
\hline $\begin{array}{l}\text { Trail status: } \\
\text { Not withdrawn } \\
\text { Withdrawn }\end{array}$ & $\begin{array}{r}19 \\
7\end{array}$ & $\begin{array}{r}17 \\
3\end{array}$ & $\begin{array}{r}18 \\
6\end{array}$ & $\begin{array}{r}16 \\
7\end{array}$ & $\begin{array}{l}70 \\
23\end{array}$ \\
\hline $\begin{array}{l}\text { Withdrawal category: } \\
\text { Complete recovery } \\
\text { Lack of response } \\
\text { Adverse events } \\
\text { Incomplete follow up }\end{array}$ & $\begin{array}{l}\overline{3} \\
1 \\
3\end{array}$ & $\frac{-}{3}$ & $\begin{array}{l}1 \\
4 \\
1 \\
-\end{array}$ & $\begin{array}{l}\overline{3} \\
3 \\
1\end{array}$ & $\begin{array}{r}1 \\
13 \\
5 \\
4\end{array}$ \\
\hline Total No of patients in treatment group & 26 & 20 & 24 & 23 & 93 \\
\hline
\end{tabular}

Table 3 Mean (SE) temperature falls by time and treatment group

\begin{tabular}{rllll}
\hline $\begin{array}{l}\text { Time } \\
\text { (min) }\end{array}$ & \multicolumn{4}{l}{ Ibuprofen dose $(\mathrm{mg} / \mathrm{kg})$} \\
\cline { 2 - 5 } & 0.625 & 1.25 & 2.5 & 5.0 \\
\hline 15 & $-0.1(0.1)$ & $-0.1(0.1)$ & $-0.2(0.1)$ & $-0.6(0.2)$ \\
30 & $-0.3(0.1)$ & $-0.5(0.2)$ & $-0.3(0.1)$ & $-0.7(0.2)$ \\
60 & $-0.9(0.1)$ & $-0.8(0.2)$ & $-0.8(0.1)$ & $-1.1(0.2)$ \\
120 & $-1.1(0.2)$ & $-1.1(0.2)$ & $-1.1(0.2)$ & $-1.9(0.2)$ \\
180 & $-0.7(0.2)$ & $-1.3(0.3)$ & $-1.3(0.2)$ & $-2.0(0.2)$ \\
\hline
\end{tabular}

\section{TEMPERATURE REDUCTION}

There was a significant decrease in temperature at three hours for all four doses of ibuprofen $(p<0.01)$ with the largest decrease for the highest dose of ibuprofen (table 3 ). The mean axillary temperatures of the children in the four randomised groups at baseline and three hours after the first ibuprofen dose are shown in fig 1. Interpretation of the data after three hours is confounded by the supplementary doses given to some children resulting in children within one randomised group having received doses which overlap with another group. Analysis of covariance showed that the influence of dose on the magnitude of the body temperature reduction was significant $(p=0 \cdot 02)$, a higher dose of ibuprofen being associated with a lower axillary temperature three hours later. The mean temperature at three hours after the $0.625 \mathrm{mg} / \mathrm{kg}$ dose was significantly greater $(p<0.01)$ than that for the $5.0 \mathrm{mg} / \mathrm{kg}$ dose and this was despite

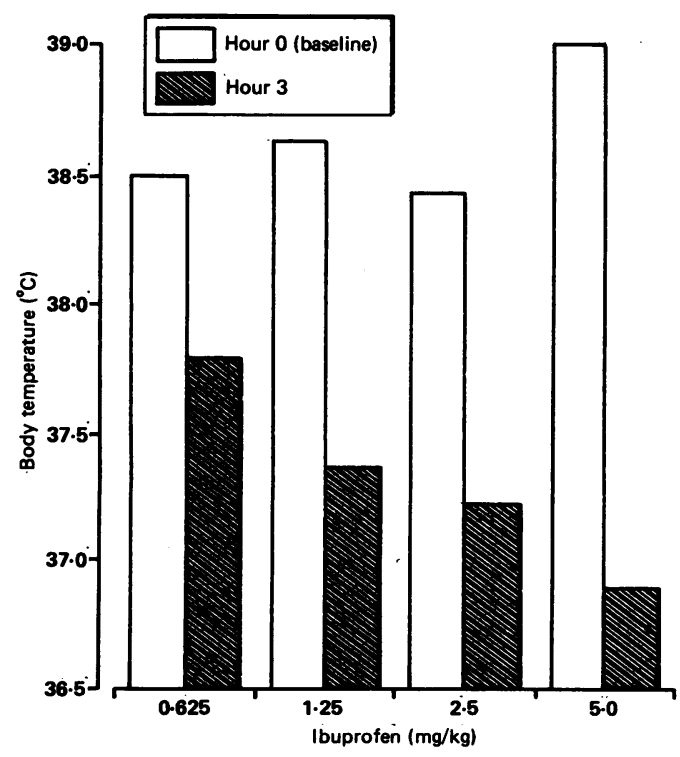

Figure 1 Mean axillary temperature $\left({ }^{\circ} \mathrm{C}\right)$ at hour 0 (baseline) and three hours after ibuprofen. the $5.0 \mathrm{mg} / \mathrm{kg}$ group starting with the highest mean baseline temperature (fig 2).

In order to assess the rate of axillary temperature reduction, mean axillary temperatures at intervals over the first three hours of the study are shown in figure 2 . In all but the $0.625 \mathrm{mg} / \mathrm{kg}$ ibuprofen group, there was a steady reduction in mean axillary temperature over the first three hours after the initial dose of ibuprofen. The mean axillary temperature of the $0.625 \mathrm{mg} / \mathrm{kg}$ group rose from $37 \cdot 5^{\circ} \mathrm{C}$ at two hours to $37 \cdot 8^{\circ} \mathrm{C}$ at three hours. The reduction in axillary temperature between two and three hours in the other three groups was only $0 \cdot 1-0.2^{\circ} \mathrm{C}$. That is to say, in the three higher dose groups most of the temperature reduction achieved by three hours (fig 1) had already occurred by two hours.

\section{SUPPLEMENTARY DOSE OF IBUPROFEN}

A total of 39 out of the 93 children warranted the 'rescue' dose at three hours after the initial, randomised dose and these children were not evenly distributed between the four randomisation groups (table 4). The higher the initial dose of ibuprofen, the more likely the children were to have an axillary temperature below $37 \cdot 2^{\circ} \mathrm{C}$ at three hours. The proportions receiving a 'rescue' dose at three hours were $68 \%, 47 \% 42 \%$, and $23 \%$ for the $0.625,1.25,2.5$, and $5.0 \mathrm{mg} / \mathrm{kg}$ ibuprofen groups respectively. These represent significant differences $(p=0 \cdot 03)$.

\section{CLINICAL SCORE}

Although there appears to be a trend with lower doses resulting in less clinical improvement, the differences between the scores at three hours did not reach significance (table 5). Interpretation of the data after three hours is confounded by the supplementary medication given to some children.

ACCEPTABILITY OF THE MEDICATION

There were no significant differences in the acceptability of medications containing diffe-

Table 4 Number of children receiving supplementary medication $(2.5 \mathrm{mg} / \mathrm{kg}$ ibuprofen at three hours if axillary temperature $\left.>37 \cdot 2^{\circ} \mathrm{C}\right)$

\begin{tabular}{lllll}
\hline & \multicolumn{4}{l}{ Ibuprofen dose (mg/kg) } \\
\cline { 2 - 5 } & 0.625 & $l \cdot 25$ & 2.5 & $5 \cdot 0$ \\
\hline $\begin{array}{l}\text { No of children given } \\
\text { supplementary dose }\end{array}$ & 15 & 9 & 10 & 5 \\
\hline
\end{tabular}




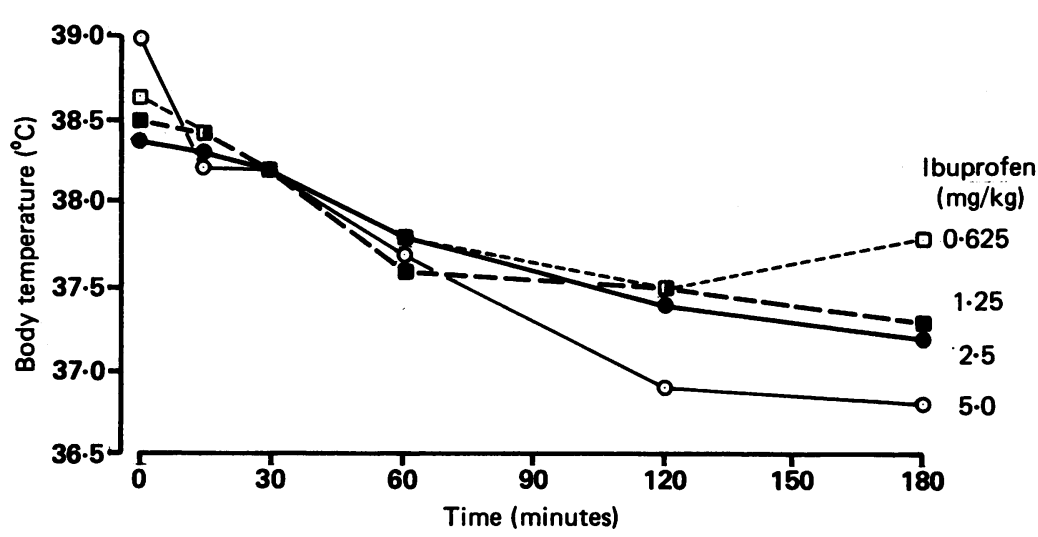

Figure 2 Reduction of axillary temperature $\left({ }^{\circ} \mathrm{C}\right)$ of children taking four different ibuprofen doses.

Table 5 Assessment of clinical condition at three hours by treatment group (a high score is more favourable)

\begin{tabular}{|c|c|c|c|c|}
\hline & \multicolumn{4}{|c|}{ Ibuprofen dose (mg/kg) } \\
\hline & 0.625 & 1.25 & $2 \cdot 5$ & $5 \cdot 0$ \\
\hline $\begin{array}{l}\text { No of children rated } \\
1=\text { Much worse } \\
2=\text { Worse } \\
3=\text { No change } \\
4=\text { Improved } \\
5=\text { Much improved }\end{array}$ & $\begin{array}{r}\text { ore: } \\
3 \\
4 \\
2 \\
7 \\
3\end{array}$ & $\begin{array}{l}1 \\
2 \\
4 \\
7 \\
6\end{array}$ & $\begin{array}{r}0 \\
1 \\
5 \\
12 \\
6\end{array}$ & $\begin{array}{r}1 \\
0 \\
5 \\
4 \\
11\end{array}$ \\
\hline Mean score & $3 \cdot 2$ & 3.8 & $4 \cdot 0$ & $4 \cdot 1$ \\
\hline
\end{tabular}

rent strengths of ibuprofen (table 6). The mean acceptability scores of the medications at first dosing were $2 \cdot 0,1 \cdot 9,2 \cdot 0$, and $2 \cdot 2$ for the 0.625 , $1 \cdot 25,2 \cdot 5$, and $5.0 \mathrm{mg} / \mathrm{kg}$ ibuprofen groups respectively $(1=$ very acceptable, $2=$ acceptable, $3=$ indifferent $)$. Overall, the medication was assessed as acceptable (that is, a score of 1-3) in $93 \%$ of the children at the time of the first dose.

\section{ADVERSE EVENTS}

A total of 19 adverse clinical events were recorded in 17 children during the study periods (table 7). Five children vomited, seven

Table 6 Acceptability of medication at first dosing (a high score represents less acceptable)

\begin{tabular}{lllll}
\hline & \multicolumn{5}{c}{ Ibuprofen dose $(\mathrm{mg} / \mathrm{kg})$} \\
\cline { 2 - 5 } & 0.625 & $1 \cdot 25$ & 2.5 & $5 \cdot 0$ \\
\hline $\begin{array}{l}\text { No of children rated at each score: } \\
\text { 1=Very definitely acceptable }\end{array}$ & 9 & 9 & 7 & 6 \\
$\begin{array}{l}\text { 2=Definitely acceptable } \\
\text { 3=Indifferent }\end{array}$ & 9 & 5 & 12 & 9 \\
$\begin{array}{l}\text { 4=Definitely not acceptable } \\
\text { 5=Very definitely not }\end{array}$ & 6 & 5 & 4 & 6 \\
$\begin{array}{c}\text { acceptable } \\
\text { Mean score }\end{array}$ & 0 & 0 & 1 & 2 \\
& 2.2 & 1.9 & 2.0 & 2.2 \\
\hline
\end{tabular}

Table 7 Summary of adverse events reported

\begin{tabular}{lcccc}
\hline & \multicolumn{5}{c}{ Ibuprofen dose } & $(\mathrm{mg} / \mathrm{kg})$ \\
\cline { 2 - 5 } & 0.625 & $1 \cdot 25$ & $2 \cdot 5$ & $5 \cdot 0$ \\
\hline Total No of patients at risk & 26 & 24 & 26 & 24 \\
Total No with adverse events: & 2 & 3 & 6 & 6 \\
Vomited/nausea & 1 & - & 1 & 3 \\
$\begin{array}{l}\text { Febrile convulsion } \\
\text { Delirious }\end{array}$ & 1 & 1 & 1 & 2 \\
$\begin{array}{l}\text { Distressed } \\
\text { Irritable/agitated }\end{array}$ & - & 1 & - & - \\
$\begin{array}{l}\text { Uncomfortable } \\
\text { Miserable }\end{array}$ & - & - & 2 & - \\
Rash & - & - & 1 & - \\
Diarrhoea & - & - & 1 & - \\
\hline Total No of reports & - & - & - & 1 \\
Total No drug related & 2 & 3 & 7 & 7 \\
\hline
\end{tabular}

children had behavioural changes ranging from 'more miserable' to 'delirious', there were five febrile convulsions (all in children admitted following a febrile convulsion), one child developed diarrhoea, and one child manifested a rash. On review of the case notes, only the fine, pink, macular rash was thought to be probably related to the treatment. The other 18 adverse events, including the five adverse events resulting in withdrawal of children from the study, were considered to be due to a worsening of the child's pre-existing febrile illness rather than due to the study medication. The incidence of drug related side effects in this study was therefore $1 \%$. The differences between the numbers of adverse clinical events reported for the four treatment groups were not significant.

\section{Discussion}

This dose ranging study was designed as a prospective, mutiple dose, parallel group, double blind trial in which children received 0.625-5.0 $\mathrm{mg} / \mathrm{kg} /$ dose of ibuprofen. Before this study the standard management of fever in our unit included $10 \mathrm{mg} / \mathrm{kg} / \mathrm{dose}$ of paracetamol every four hours and it was therefore considered unethical to include a placebo control group in the trial. However, in view of the justifiable concern that children randomised to receive the lower dose ibuprofen regimens might actually receive an ineffective dose, a 'safety net' allowed for supplementary dosing with ibuprofen should the child remain febrile.

This study showed clear dose dependent effects of ibuprofen on the absolute magnitude of temperature reduction, the pattern of temperature change with time, and the need for the child to be given an extra 'rescue' dose of medication. Ibuprofen suspension was equally effective irrespective of age within the range studied.

To determine the minimum effective dose requires criteria to be set that define efficacy. Clearly time has to be included in any definition. An agent that works too slowly will not be clinically useful while a drug that works quickly but then fails to prevent the pyrogen, or the body's physiological response to a falling body temperature, raising body temperature again almost immediately is also unsatisfactory. It was therefore decided to adopt for the study protocol a reduction of $1^{\circ} \mathrm{C}$ or more in axillary temperature at three hours as the principal measure of antipyretic efficacy. In the $5 \mathrm{mg} / \mathrm{kg}$ dose group, $82 \%$ of the children achieved a temperature reduction of at least this size (fig 3).

In a study directly comparing a $5 \mathrm{mg} / \mathrm{kg} /$ dose of ibuprofen and a $10 \mathrm{mg} / \mathrm{kg} /$ dose of paracetamol in febrile children, it was shown that both were superior to placebo and that $5 \mathrm{mg} / \mathrm{kg}$ ibuprofen suspension was as well tolerated as 10 $\mathrm{mg} / \mathrm{kg}$ paracetamol elixir. ${ }^{8}$ Two other trials in children have shown that a slightly larger dose of $6 \mathrm{mg} / \mathrm{kg}$ ibuprofen as elixir' ${ }^{9}$ tablets ${ }^{6}$ was as effective in reducing temperature as $10 \mathrm{mg} / \mathrm{kg}$ aspirin or $12.5 \mathrm{mg} / \mathrm{kg}$ paracetamol respectively. A dose of $5-10 \mathrm{mg} / \mathrm{kg}$ ibuprofen is recommended for children with Still's disease. ${ }^{10}$ In the study by Walson et al $10 \mathrm{mg} / \mathrm{kg}$ ibuprofen produced significantly greater and longer last- 


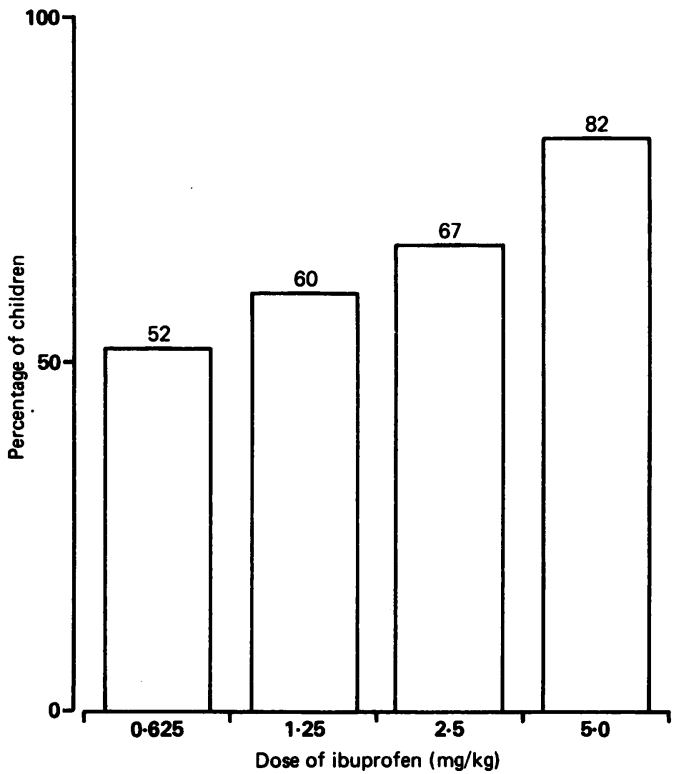

Figure 3 Percentage of children showing a temperature reduction of $1^{\circ} \mathrm{C}$ or more at three hours by dose of ibuprofen.

ing fever control than $10 \mathrm{mg} / \mathrm{kg}$ paracetamol. ${ }^{8}$ However, doses of $15 \mathrm{mg} / \mathrm{kg}$ paracetamol are commonly prescribed.

Although 39 children warranted 'rescue' treatment, only five of these children had received an initial $5 \mathrm{mg} / \mathrm{kg}$ dose of ibuprofen. The 'rescue' medication was given if the child's axillary temperature remained above $37 \cdot 2^{\circ} \mathrm{C}$ three hours after the initial randomised dose and the apparent 'failure' of the $5 \mathrm{mg} / \mathrm{kg}$ dose in these five children must be viewed against this very strict temperature criterion and in comparison with other antipyretic measures. The mean baseline axillary temperature was $39^{\circ} \mathrm{C}$ in the $5 \mathrm{mg} / \mathrm{kg}$ ibuprofen group of our study. In an earlier study in which children had a mean baseline oral temperature of $39^{\circ} \mathrm{C}$, the mean oral temperature three hours later remained at $38.7^{\circ} \mathrm{C}$ if only nursing measures were used and was $37 \cdot 8^{\circ} \mathrm{C}$ if $10 \mathrm{mg} / \mathrm{kg}$ paracetamol had been given. ${ }^{8}$

Finally, the $5 \mathrm{mg} / \mathrm{kg}$ ibuprofen dose did not compare unfavourably in our study with the weaker doses in acceptability or in the nature of adverse events.

1 Hull D. Fever-the fire of life. Arch Dis Child 1989;64:

2 Tarlow M. Reye's syndrome and aspirin. BMF 1986;292: $1543-4$.

3 Adams SS, McCullough KF, Nicholson JS. The pharmacological properties of ibuprofen, an anti-inflammatory, cological properties of ibuprofen, an anti-inflammatory,
analgesic and antipyretic agent. Arch Int Pharmacodyn Ther analgesic and antipy

4 Brooks CD, Schlagel CA, Sekhar NC, Sibota JT. Tolerance and pharmacology of ibuprofen. Current Therapeutic Research 1973;15:180-90.

5 Wilson G, Guerra AJMS, Santos NT. Comparative study of the antipyretic effects of ibuprofen (oral suspension) and paracetamol (suppositories) in paediatrics. $\boldsymbol{f}$ Int Med Res 1984;12:250-4.

6 Simila S, Kouvalainen K, Keinanen S. Oral antipyretic therapy: evaluation of ibuprofen. Scand $\mathcal{F}$ Rheumatol 1976; 5:81-3.

7 Amdekar YK, Desai RZ. Antipyretic activity of ibuprofen and paracetamol in children with pyrexia. Br $\mathcal{f}$ Clin Pract 1985;39:140-3.

8 Walson PD, Galletta G, Branden NJ, Alexander L. Ibuprofen, acetaminophen and placebo treatment of febrile children. Clin Pharmacol Ther 1989;46:9-17.

9 Heremans G, Dehaen F, Rom N, Ramet J, Verboven $M$ Loeb H. A single-blind parallel group study investigating the antipyretic properties of ibuprofen syrup versus acetylsalicylic acid syrup in febrile children. Br $\mathcal{F}$ Clin Pract 1988;42:245-7.

$10 \mathrm{BMA}$ and Pharmaceutical Society. Drugs used in rheumatic diseases and gout. In: Prasad $\mathrm{AB}$, ed. British national formulary. No 19. London: BMA and Pharmaceutical Society of Great Britain, 1990:338-40.

\section{Commentary}

NEW DRUG FOR OLD?

Fever is universal. We all experience it from time to time and the average child in Britain is given an antipyretic drug on four or five days a year. ${ }^{1}$ Since the demise of aspirin for childhood fever in 1986, paracetamol has had the field to itself. Fever in itself is unlikely to be harmful. As a response to infection it almost never rises above $41^{\circ} \mathrm{C}$ and, provided dehydration is avoided and heat loss is not prevented by overheating or overclothing, fever of that degree is not damaging. ${ }^{2}$ Even in those prone to febrile convulsions, treatment of fever does not seem to prevent attacks. ${ }^{3}$ The reasons for giving an antipyretic drug are to relieve discomfort and to relieve the anxiety felt particularly by parents (and by medical and nursing attendants). Do we need a new drug for this purpose and what risk are we prepared to take to develop one?

Paracetamol was first used in 1893 and has been in regular use since $1949 .{ }^{4}$ It has so far not been associated with serious toxicity in therapeutic dosage and, despite its ready availability, overdosage has not been a serious problem in children. ${ }^{5}$ It is effective. ${ }^{6-8}$

What properties should a drug have in order for it to replace paracetamol as an antipyretic for children? Laying aside considerations of presentation and expense, I suggest the following: (i) it should be demonstrably more effective in relieving discomfort and (ii) it should be free of serious toxicity when given to very large numbers (millions) of children. Therein lies the rub. Does a possibly slightly greater temperature reduction with ibuprofen translate into significantly greater comfort for children in practice? There seems to be little evidence on that point. The second of these conditions is, of course, impossible to satisfy without taking the risk and whether the risk is worthwhile depends on the seriousness of the condition to be treated and the effectiveness of present treatment. If aspirin were a certain cure for leukaemia, for instance, its association with Reye's syndrome would be disregarded in that context because the benefit would far exceed the risk. The risk-benefit equation is very different for childhood fever.

So far there is no known serious toxicity for ibuprofen but it has not until very recently been used in very large numbers of children. It has been used in the treatment of juvenile chronic arthritis for 11 years but only recently been used as an antipyretic. ${ }^{9}$ Aspirin was in use for over $\mathbf{8 0}$ years before its use in children was discontinued. Drug surveillance is now much improved but to recommend any drug for use in a condition that affects virtually all children several times a year is to suggest an experiment. There are many other non-steroidal antiinflammatory drugs, the manufacturers of at least one of which have to my knowledge seriously considered promoting its use for childhood fever but have so far not done so, so the 